R. Stephan, R. de Andrade Jr., A. C. Ferreira, F. Costa, O. Machado Laboratory of Applied Superconductivity - Federal University of Rio de Janeiro

\title{
MAGLEV-COBRA: AN URBAN TRANSPORTATION SYSTEM FOR HIGHLY POPULATED CITYES
}

Дата поступления 04.06.2015

Решение о публикации 03.07.2015

Дата публикации 22.12.2015

Abstract: This paper describes the construction and operation of a superconducting magnetically levitated vehicle applied to urban transportation. The technology was tested with a full-scale prototype named MagLev-Cobra. Comparisons with wheel and rail technology, high speed MagLev and other MagLev technologies are presented and application niches identified. The steps for commercialization will also be addressed.

Keywords: Magnetic Levitation, Superconductivity, Linear Traction, MagLev-Cobra, Urban Transportation.

\section{Introduction}

The need of high speed non-polluting transportation systems has drawn the world attention to MagLev trains that can travel at speeds of $600 \mathrm{~km} / \mathrm{h}$ and use electricity as power supply. For connections up to $1000 \mathrm{~km}$, high speed trains can offer advantages in terms of reliability, time, comfort and cost in comparison with airplanes and other transportation means [1].

On the other hand, the need of efficient public urban transportation, nonpolluting and with competitive construction cost is one of the priorities of the modern world, where great part of the population live in big cities. The MagLev technology also offers construction and operational advantages in this case [2].

Research projects, prototypes and commercial applications are scattered worldwide. This paper presents an overview of the basic principles and applications of MagLev trains, focusing special attention on the MagLev-Cobra project. A prototype was tested in a full-scale 200 meters long line. Comparisons with other MagLev technologies are presented and application niches identified. The steps for commercialization will also be addressed in this paper. 


\section{Levitation methods}

The promising magnetic levitation (MagLev) techniques for applications in mass transportation can be summarized into three groups, described below.

\section{Electro Dynamic Levitation (EDL) - repulsion force}

This type of levitation requires the motion of a magnetic field in the proximity of a conductive material. The Japanese levitation train JR-MagLev [3] is grounded on this principle. There is a double line for demonstration and test, 42,8 km long, in Yamanashi, a town between Tokyo and Osaka. The world record of $603 \mathrm{~km} / \mathrm{h}$ was reached there in April 2015. Japan plans to extend this test line to replace the Shinkansen (high speed wheel-rail train) connecting Tokyo-Nagoya in 2027 and Nagoya-Osaka in 2045. The technology has not yet been deployed commercially.

According to Faraday's law, the relative movement of a magnetic field in the proximity of a conductor will induce currents in it. These induced currents will generate a new magnetic field in opposition to the rate of change of the first (Lens's law), resulting in repulsion and drag forces. The repulsion force can be used for suspension. This configuration is vertically poor damped and the lateral stability needs a special winding arrangement. Moreover, at stand still there is no levitation force, therefore this method needs supporting wheels until the vehicle reaches the levitation velocity.

\section{Electro Magnetic Levitation (EML) - attraction force}

This type of levitation has in the German proposal of levitation train Transrapid [4], which is commercially deployed since 2003 in a connection of $30 \mathrm{~km}$ in double line, between Shanghai Pudong International Airport and Shanghai Lujiazui, a financial district, its best showcase [5].

The underlying physical basis of this application exploits the attraction force that exists between an electromagnet and a ferromagnetic material. The stabilization, in this case, is only possible with a properly tuned feedback control system.

\section{Superconducting Magnetic Levitation (SML) - repulsion and attraction forces}

This type of levitation is based on the diamagnetic property of superconducting materials known as Meissner effect. The magnetic field in the interior of a superconductor is zero in the presence of a permanent magnet, producing a repulsive force. In the case of type II superconductors, this exclusion is partial, which reduces the levitation strength, but leads to an attraction force given by the so-called "pinning effect". The combination of both these forces leads to stability [6],[7]. This property, which represents a major difference compared to the EDL and EML methods, could only be properly exploited from the late 20th century with the advent of new magnetic materials, 
such as $\mathrm{Nd}_{2} \mathrm{Fe}_{14} \mathrm{~B}$ (Nd-Fe-B) [8], and blocks of High Temperature Superconductors (HST), such as $\mathrm{YBa}_{2} \mathrm{Cu}_{3} \mathrm{O}_{\mathrm{X}}$ (YBCO) [9]. Brazil, with the MagLev-Cobra project developed a real-scale demonstration line of this technology. The physical aspects of this project were already addressed in some publications [10]-[16]. Other research groups are also pursuing this technology [17], [18]. Therefore, perspectives of innovation, originality and technical development can be foreseen.

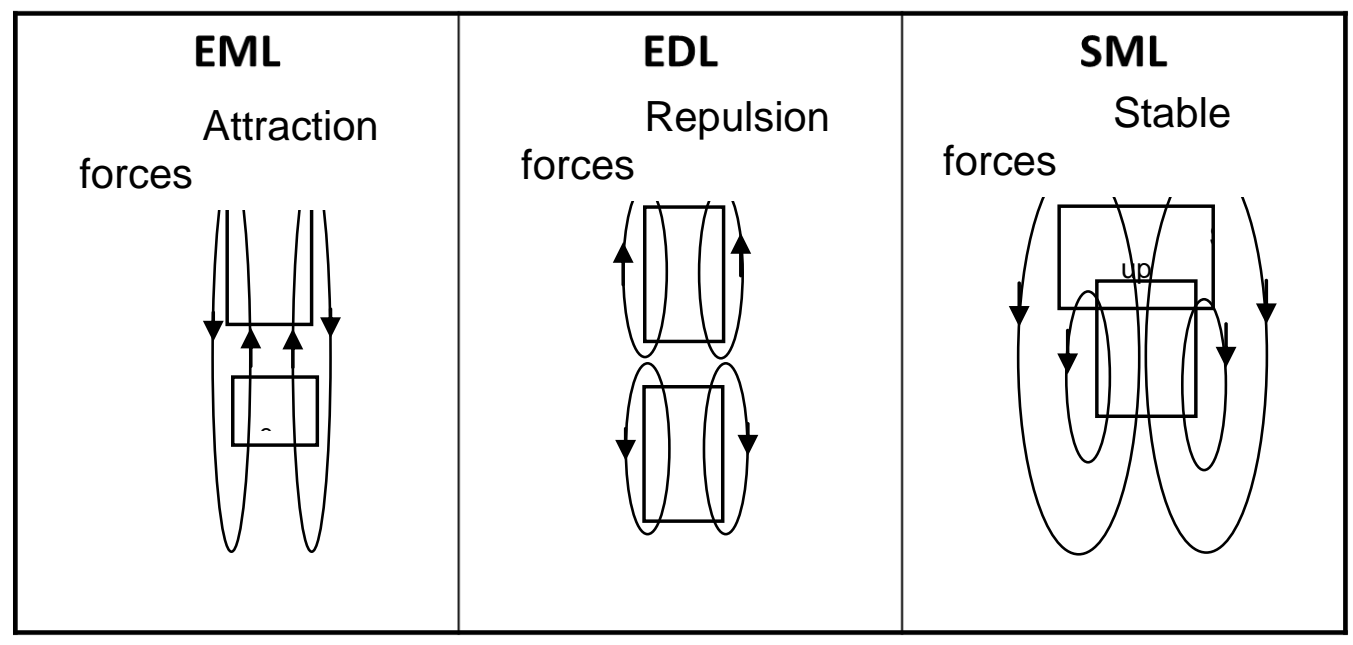

Fig. 1. Magnetic Levitation Methods

\section{Linear traction}

Since there is no contact between rail and wheels, the traction of MagLev trains occurs through the so-called linear motors, which can be understood as rotary cylindrical motors of infinite radius. Thus, the rotational movement becomes a translational one.

Similarly to cylindrical motors, linear motors can be classified as AC (Alternating Current) or DC (Direct Current), according to their electric energy supply. Since the advent of power electronic converters, that allow the easy control of AC machines, DC motors have been gradually substituted and do not present any advantage for new applications.

Induction Machines (IM) and Synchronous Machines (SM) represent the two first options in the case of AC supply. The winding connected to the power supply is called armature. In AC cylindrical motors, the armature is always located in the stator. Both IM and SM have identical armature windings, the difference lying in the rotor: a simple set of conductors or conducting sheets for the IM, a magnetic field for the SM. This magnetic field can be given by permanent magnets, electro magnets or superconducting coils. This extra requirement in compensated for the easier control of SM when compared with the control of IM. 
In the case of linear motors, the armature can be located either in the moving part or in the stationary one. The nomenclature used is 'short armature', for the former, or 'long armature', for the latter.

To supply energy to the moving part of linear motors, some kind of electric contact is necessary. Rails or catenaries can be employed, but, in any case, the higher the speed, the more challenging is to continuously maintain the electric contact. Therefore, for high speed MagLev trains $(\sim 500 \mathrm{~km} / \mathrm{h})$, the long armature linear motor, that does not need moving supply contacts, is the natural choice. On the other hand, for low speed applications, the short armature presents economical advantages, since it avoids the expensive windings distributed along the track. Moreover, the energy supply can be easily achieved by contact or by opportunity at the stops in stations charging supercapacitors.

The points raised in the previous paragraphs are summarized below:

- The armature windings of SM and IM are identical.

- IM are simpler than SM, since the latter needs a source of magnetic field.

- Short armature is much less expensive than long armature.

- Long armature is the best choice for very high speeds.

- The control of SM is more straightforward than the control of IM.

This leads to the conclusion that for commercial applications short armature Linear Induction Motors (LIM) are the best choice for the traction of low speed MagLev trains and long armature Linear Synchronous Motors (LSM) the best choice for the traction of high speed MagLev trains.

\section{The maglev-cobra project}

MagLev-Cobra is a vehicle with multiple short units, allowing curves of 50 meters radius, ramps of $10 \%$ and velocities up to $70 \mathrm{~km} / \mathrm{h}$. When these short units are connected, the vehicle resembles a 'snake' or 'cobra' in Portuguese.

The levitation technology is based on the properties of High Temperature Superconductors (HTS) and the magnetic field of Nd-Fe-B magnets. These materials were made available at the end of last century and until today there is no such system in commercial use.

A linear motor gives the traction. Since this propulsion method only needs electric energy, which is mainly generated by hydro power plants in Brazil, the MagLev-Cobra has low polluting effect.

Due to the low noise emission level, the vehicle can run inside cities on elevated structures. The estimated construction costs are $1 / 3$ of that necessary for subways.

Moreover, the energy consumption and the maintenance costs are lower than that of a LRV (Light Rail Vehicle) since no mechanical contacts and rotational parts are necessary. 
The proposed vehicle gives a futuristic view along its way, matching high technology, modern design, environmental restrictions and social requirements.

Maglev-Cobra technology is summarized in Figure 2.

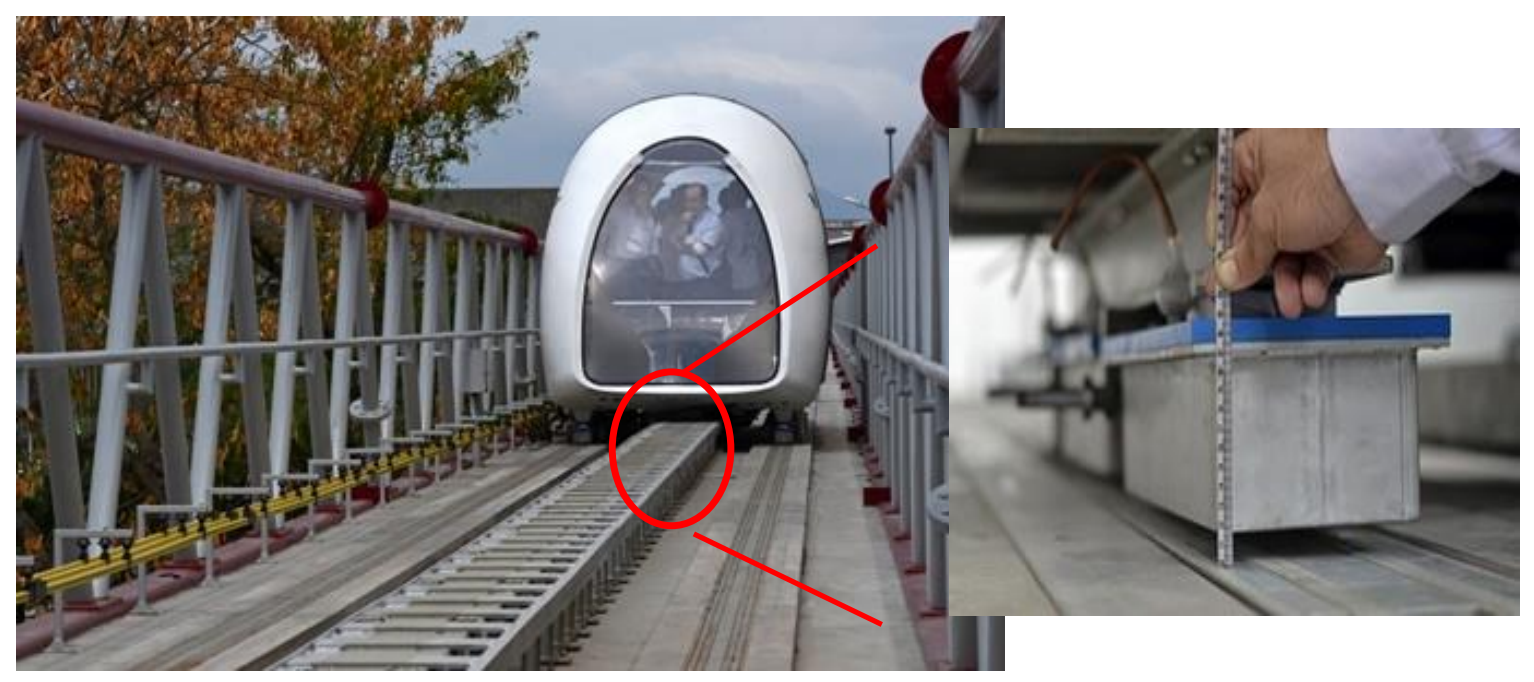

Fig. 2. Graphical abstract of the MagLev-Cobra project

The vehicle is traveling on an elevated line, above pedestrians and do not disturbing the city life. In the center, is the secondary of the Linear Induction Motor (LIM) used for the traction. To the right and left of the linear motor, is the line of permanent magnets. The highlight shows the cryostat (high quality thermos bottles) inside of which are superconductors cooled with liquid nitrogen at minus $196^{\circ} \mathrm{C}$, providing a levitation height of the order of $1 \mathrm{~cm}$.

\section{Construction Advantages}

- $\quad$ Distributed load: On traditional vehicles, the load is concentrated at the point of contact between wheel and rail. On the other side, for MagLev vehicles, the load is distributed. The efforts on the supporting structure are therefore reduced, implying a lighter and cheaper infra-structure.

- $\quad$ Reduced weight: As the MagLev-Cobra vehicle do not need wheels, trucks and rotational motors, it weighs less than a Light Rail Vehicle (LRV). Moreover, the iron rails, sleepers and stones necessary to the infra-structure of a LRV are heavier than the magnetic rail of the MagLev-Cobra system.

- $\quad$ Reduced cross section: Again the absence of wheels, trucks and rotational motors make the cross section of the MagLev-Cobra half the usual one and, moreover, practically circular. These characteristics represent a big advantage for the construction of tunnels. 
- $\quad$ Reduced radius: The MagLev-Cobra will be constructed with modules of just $1.5 \mathrm{~m}$ length. Therefore, curves with $50 \mathrm{~m}$ radius are acceptable.

- Higher declivity: When based on friction, the maximal declivity of a track is $4 \%$. The linear motor traction of MagLev vehicles allows declivities of $10 \%$, just limited by the comfort of passengers.

\section{Operational Advantages}

- $\quad$ Reduced energy consumption: The energy to levitate the MagLevCobra vehicle is just that necessary to refrigerate the YBCO superconductors with liquid Nitrogen. These superconductors are arranged inside cryostats and, therefore, the consumption is extremely low, representing an advantage when compared with the electromagnetic (EML) or electro dynamic (EDL) levitation methods. For the traction, as the resistance is limited to the air friction (there is no drag force or Coulomb friction) and the velocity is low $(<70 \mathrm{~km} / \mathrm{h})$, the mean energy consumption per passenger is lower in comparison with buses and cars.

- $\quad$ Reduced $\mathrm{CO}_{2}$ emission: As the MagLev-Cobra needs less energy and is supplied with electric energy, which in countries like Brazil comes mainly from renewable sources, the $\mathrm{CO}_{2}$ emission is extremely low.

- $\quad$ Reduced noise: Without friction and running at low speeds, the noise produced is negligible and the vehicle does not disturb the city life, being appropriate to run on elevated lines or along rivers or channels at ground level.

- $\quad$ Easy of switch: As reported in [30], the change of direction can be achieved with electromagnets, substituting the traditional slow mechanical solution.

- $\quad$ Easier maintenance: The linear motor used for the traction do not have moving parts, making the maintenance easier than that of cylindrical motors with bearings and mechanical wear. The magnetic rail requires less maintenance than the usual rail system with dormant and alignment procedures.

\section{Application niches}

The power required to levitate a vehicle based on the EML or EDL methods is approximately $1.7 \mathrm{~kW} / \mathrm{t}[19]$. On the other hand, the power necessary to run a MagLev vehicle at a constant speed $v$ is mainly due to the air resistance and approximately proportional to $v^{3}$. At high speeds $(>250 \mathrm{~km} / \mathrm{h})$, the levitation power becomes comparatively small in relation to the power required for traction [19], pointing to long-distance calls, where the high speed has a major role. In the case SML, the power needed for levitation is practically zero, however, the line of magnets needed to promote the diamagnetic effect is more expensive than the infrastructure of the options EML or EDL. Short distances between stations and low speeds predominate in urban transportation, opening 
up here an application niche for SML. Therefore, the proposed MagLev-Cobra vehicle for urban transportation is based on SML. For high-speed connection, EML and EDL are the most appropriate technologies.

\section{Implementation steps}

The development of any new engineering product can be generally divided in four steps:

\section{Step 1: Proof of concept}

Usually a small scale prototype consolidates this step. Universities are probably the best place for this initial development.

\section{Step 2: Functional prototype}

Here a full scale prototype must be constructed and many engineering problems are already faced: the product design, the construction methods, the industrial partners, the financial support. This phase is prone of possibilities for patent applications.

\section{Step 3: Operational prototype}

The full scale prototype is not enough. The operational characteristics must be known and well tested. In other words, the equipment must be certified. In the specific case of a transportation vehicle, safety issues are a main concern: what happens if there is a brake failure, if there is a short circuit, if there is a storm, if the door does not close or open, if there are too many passengers, and many other questions.

\section{Step 4: Industrialization}

Finally, the series production and commercialization can start. This last step represents a big challenge and by no means a trivial one.

The man force, the money, the difficulties, everything increases at each step. For the MagLev-Cobra technology:

Step 1 (2000-2006) was concluded in 2006 and reported in [20]-[23].

Step 2 (2008-2012). The gap of two years between these steps is due to difficulties to raise funds. In fact, $4 \mathrm{M} \mathrm{R} \$$ was necessary for this part, approximately 10 times more than the money applied in step 1. It consists of a 12 meters long line to verify the technical characteristic of the system [24].

Step 3 (2014-2015). Based on the experience of step 2, the next move will test the operation of the vehicle in everyday use [25], [26]. For that, a line of $200 \mathrm{~m}$ connecting two units of the Federal University of Rio de Janeiro has been constructed.

Step 4 (starting at 2016). After the improvements that will result from the experience of step 3, the technology will be mature for commercialization.

This evolution is summarized in Figure 3. 


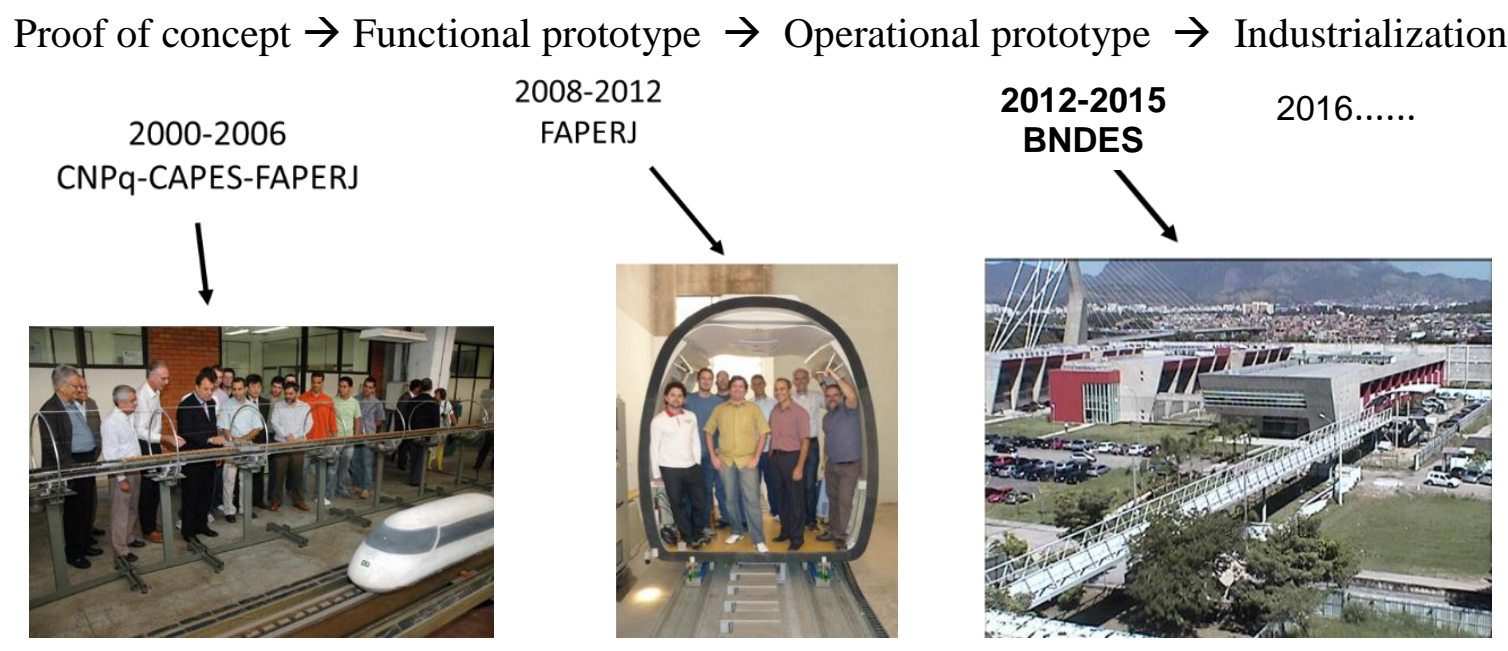

Fig. 3. The evolution of the MagLev-Cobra project

\section{Conclusion}

The MagLev-Cobra Project satisfies the requirements of a sustainable project, since it fulfils ecological, economic and social aspects:

- $\quad$ Low ecological impact low energy consumption low audible noise low impact in the civil engineering construction

- $\quad$ Economic advantages cheaper than a subway low maintenance costs

- $\quad$ Social extent solves the urban transportation system of large cities favours the generation of qualified jobs and industrialization

\section{References}

1. ATKINS High Speed Line Study - Strategic Rail Authority, UK, 2002.

2. Stephan R. M., de Andrade Jr. R., Ferreira A. C. IEEE Vehicular Technology Magazine, 2012, v.7, pp. 122- 127.

3. URL: http://www.rtri.or.jp (02/01/2011).

4. URL: http://www.transrapid.de (02/01/2011).

5. URL: http://www.smtdc.com (02/01/2011).

6. Moon F. C Superconducting Levitation. NY, 1994.

7. Hull J. R., Murakami M. Proceedings of the IEEE, 2004, vol. 92, pp. 1705-1718.

8. Thompson M. T. Proceedings of the IEEE, 2009, vol. 97, no. 11, pp. 1758-1767. 
9. Wu M. K., Ashburn J. R., Torng C. J., Hor P. H., Meng R. L., Gao L., Huang Z. J., Quang Y. Q., Chu C. W. Physical Review Letters, 1987, vol. 58, no.9, pp. 908-910.

10. Dias D. H. N., Motta E. S., Sotelo G. G., de Andrade Jr. R . Superconductor Science and Technology, 2010, v. 23, pp. 75013.

11. Dias D. H. N., Motta E. S., Sotelo G. G., de Andrade Jr. R., Stephan, R. M., Kuehn L., de Haas O., Schultz L. IEEE Transactions on Applied Superconductivity, 2009, v.19, pp. 2120-2123.

12. Sotelo G. G., de Andrade Jr. R., Ferreira A. C. IEEE Transactions on Applied Superconductivity, 2009, v. 19, pp. 2083-2086.

13. Kasal R. B., de Andrade Jr. R., Sotelo G. G., Ferreira, A. C. IEEE Transactions on Applied Superconductivity, 2007, v. 17, pp. 2158-2161.

14. Stephan R. M., Nicolsky R., Neves M. A., Ferreira A. C., de Andrade Jr. R., Moreira M.A.C., Rosário M. A. P., Machado O. J. Physica. C, Superconductivity, 2004, v. 408, pp. 932-934.

15. Stephan R. M., de Andrade Jr. R., Santos G., Neves M. A., Nicolsky R. Physica. C, Superconductivity, 2003, v.386, pp. 490-494.

16. de Andrade Jr. R., Santos G., Rosário M. A. P., Neves M. A., Pereira A. S., Ripper A., Costa G. C., Nicolsky R., Stephan R. M. IEEE Transactions on Applied Superconductivity, 2003, v.13, pp. 2271-2274.

17. Wang S., Wang J., Wang X., Ren Z., Zeng Y., Deng C., Jiang H., Zhu M., Lin G., Xu Z., Zhu D., Song H. IEEE Transactions on Applied Superconductivity, 2003, vol. 13 , no. 2, part. 2, pp. 2134-2137.

18. Schultz L., de Haas O., Verges P., Beyer C., Rohlig S., Olsen H., Kuhn L., Berger D., Noteboom U., Funk U. IEEE Transactions on Applied Superconductivity, 2005, vol. 15, no. 2, part 2, pp. 2301-2305.

19. Schach R., Jehle P. Naumann R. Transrapid und Rad Glanz Hochgeschwindigkeitsbahn: gesamtheitlicher Systemvergleich [Transrapid und Rad Shine Hochgeschwindigkeitsbahn: gesamtheitlicher Systemvergleich]. Berlin, 2006 [Deutsch].

20. Nicolsky R., Stephan R. M., de Andrade Jr. R., Ferreira A. C. The Brazilian Project for a Superconducting Magnetic Levitation Train. 16th Int. Conf. on Magnetically Levitated Systems and Linear Drives. Rio de Janeiro, 2000, vol.1, pp. 179-182.

21. Nicolsky R., Stephan R. M., Ferreira A. C., de Andrade Jr. R., Moreira M. A. C., Rolim L. G. B., Neves M. A., Rosário M. A. P. The Current State of the Brazilian Project for a Superconducting Magnetic Levitation Train. 17th Int. Conf. on Magnetically Levitated Systems and Linear Drives. CD-ROM, Lausanne, 2002.

22. Stephan R. M., Ferreira A. C., de Andrade Jr. R., Moreira M. A. C., Rolim L. G. B., Neves M. A., Rosário M. A. P., Machado O. J., Nicolsky R. 
A Superconducting Magnetic Levitation Train Prototype in Closed Loop Track. 18th International Conference on Magnetically Levitated Systems and Linear Drives. CD-ROM, Shanghai, 2004.

23. Stephan R. M., Ferreira A. C, Moreira M. A. C., de Andrade Jr. R, Nicolsky R. The Brazilian SQL MagLev Train Prototype. 8th International Symposium on Magnetic Suspension Technology. Dresden, 2005, vol. 1, pp. 3944.

24. Stephan R. M., David E. G., de Andrade Jr. R., Sotelo G. G., Machado O. J. A Full-Scale Module of the MagLev-Cobra HTS-Superconducting Vehicle 20th International Conference on Magnetically Levitated Systems and Linear Drives. CD-ROM, San Diego, 2008.

25. Stephan R. M., David E. G., Haas O. MagLev-Cobra: an urban transportation solution using HTS superconductors and permanent magnets. 20th International Conference on Magnetically Levitated Systems and Linear Drives. CD-ROM, San Diego, 2008.

26. Stephan R. M., Sucena M. P., Krueger R. The Opportunity of MagLev in Respect to the Upcoming Mega Events in Brazil. 5th International Symposium Networks for Mobility. CD-ROM, Stuttgart, 2010.

Acknowledgements: To FAPERJ, BNDES, CNPq and CAPES for the financial support.

\section{Information about authors:}

Richard Magdalena STEPHAN, Dr.-Ing., professor, UFRJ, E-mail: richard@ dee.ufrj.br Rubens de ANDRADE Junior, D.Sc., professor, UFRJ, E-mail: randrade@ dee.ufrj.br Antonio Carlos FERREIRA, Ph.D., professor, UFRJ, E-mail: ferreira@coep.ufrj.br Felipe dos Santos COSTA, M.Sc., engineer, UFRJ, E-mail: felipe@ pee.ufrj.br Ocione José MACHADO, B.Sc., technician, UFRJ, E-mail: ocione@dee.ufrj.br

(C) STEPHAN R., De ANDRADE R., FERREIRA A., COSTA F., MACHADO O., 2015 